\title{
Gender differences in coronary artery diameters and survival results after off-pump coronary artery bypass (OPCAB) procedures
}

\author{
Tomasz Urbanowicz $^{1 \wedge}$, Michał Michalak ${ }^{2}$, Anna Olasińska-Wiśniewska ${ }^{1}$, Assad Haneya ${ }^{3}$, \\ Ewa Straburzyńska-Migaj ${ }^{4}$, Michał Bociański ${ }^{1}$, Marek Jemielity ${ }^{1}$
}

${ }^{1}$ Department of Cardiac Surgery and Transplantology, Poznan University of Medical Sciences, Poznan, Poland; ${ }^{2}$ Department of Computer Science and Statistics, Poznan University of Medical Sciences, Poznan, Poland; ${ }^{3}$ Klinik für Herz- und Gefäßchirurgie, Universitatklinikum SchleswigHolstein, Kiel, Germany; ${ }^{4} 1$ st Department of Cardiology, Poznan University of Medical Sciences, Poznan, Poland

Contributions: (I) Conception and design: T Urbanowicz, M Michalak, A Haneya; (II) Administrative support: M Jemielity; (III) Provision of study materials or patients: T Urbanowicz, A Olasińska-Wiśniewska, M Bociański; (IV) Collection and assembly of data: T Urbanowicz, M Michalak, A Olasińska-Wiśniewska; (V) Data analysis and interpretation: T Urbanowicz, M Michalak, A Olasińska-Wiśniewska, A Haneya, E StraburzyńskaMigaj, M Jemielity; (VI) Manuscript writing: All authors; (VII) Final approval of manuscript: All authors.

Correspondence to: Tomasz Urbanowicz, MD, PhD. Department of Cardiac Surgery and Transplantology, Poznan University of Medical Sciences, $1 / 2$ Dluga Street, 61-848 Poznan, Poland. Email: tomasz.urbanowicz@skpp.edu.pl.

Background: Cardiovascular disease is still the leading cause of death among men and women. The gender related survival differences following off-pump surgery was the subject of the study with relation to coronary arteries diameters according to sizes of intraluminal shunts applied during surgery.

Methods: We retrospectively collected data of 2,772 patients who were referred for surgical revascularization in our department between 2010 and 2018 with mean follow up period of 76 months. Patients underwent coronary artery bypass grafting with off-pump technique (OPCAB) with intraluminal shunts application during each anastomosis.

Results: The multivariate Cox's proportional hazards model revealed male sex as significant all-cause mortality risk factor [hazard ratio $(\mathrm{HR})=4.62 ; 95 \%$ confidence interval $(\mathrm{CI}):(3.12-6.83)$ ]. The survival proportion was significantly lower in male than female ( $73 \%$ vs. 94\%; $\mathrm{P}<0.0001)$ within 130 months of follow up despite favorable results of coronary artery diameters. Mean \pm standard deviation (SD) diameters of coronary arteries measured by shunts applied during off-pump revascularization were $1.81 \pm 0.28 v s$. $1.7 \pm 0.26 \mathrm{~mm}(\mathrm{P}<0.0001)$ for left anterior descending artery $(\mathrm{LAD})$ anastomosis, $1.78 \pm 0.27$ vs. $1.71 \pm$ $0.29 \mathrm{~mm}(\mathrm{P}<0.0001)$ for circumflex artery $(\mathrm{Cx})$ anastomosis and $1.77 \pm 0.28$ vs. $1.72 \pm 0.31 \mathrm{~mm}(\mathrm{P}>0.05)$ for right coronary artery (RCA) anastomosis in men and women subgroups, respectively.

Conclusions: Female sex is associated with better overall late survival following surgical revascularization despite smaller diameters of coronary arteries in direct measurement with the use of intraluminal shunt application.

Keywords: Survival; gender differences; off-pump coronary artery bypass (OPCAB); coronary diameter

Submitted Nov 23, 2020. Accepted for publication Feb 15, 2021.

doi: $10.21037 /$ jtd-20-3356

View this article at: http://dx.doi.org/10.21037/jtd-20-3356

$\wedge$ ORCID: 0000-0001-8080-2764. 


\section{Introduction}

Coronary artery disease (CAD) is still the leading cause of mortality in developed countries (1). The gender differences in development of atherosclerosis and prevalence followed by worse clinical outcomes were reported (1-7). The first major adverse cardiovascular event (MACE) is diagnosed almost 10 years earlier in males than in females $(2,3)$. The mortality risk from CADs is higher in females comparing with men despite similar atherosclerotic plaque morphology. Women are characterized by worse revascularization outcomes and higher all-cause mortality than men which may be related to smaller coronary arteries diameters (4-6). Previous studies included non-direct evaluations with the use of computed tomography or coronary angiography. We performed late all-cause survival analysis in relation to gender differences and aimed to find an objective direct method of coronary artery diameter assessment. We present the following article in accordance with the STROBE reporting checklist (available at http://dx.doi.org/10.21037/ jtd-20-3356).

\section{Methods}

We retrospectively collected data of 2,772 consecutive patients [2,194 male (79\%) and 578 females (21\%)] with mean \pm standard deviation (SD) age of $64 \pm 9$ vs. $67 \pm 8$ years operated in our department. The mean body surface area (BSA) was $1.95 \pm 0.2$ and $1.7 \pm 0.3 \mathrm{~m}^{2}$ in men and women, respectively. Co-morbidities were analyzed. The detailed data are presented in Table 1.

All procedures were performed in a planned matter as a "beating heart surgery" which included off-pump coronary artery bypass $(\mathrm{OPCAB})$ procedures. Urgent surgeries and on-pump procedures without clamping were not included into the study. Patients presenting with unstable angina included into the study, were operated within $24 \mathrm{hrs}$ after admission.

The left mammary artery and parts of saphenous vein for venous grafts were harvested. Intravenous heparin was used to achieve therapeutic activated clotting time (ACT) with a mean value \pm SD of $420 \pm 40 \mathrm{~s}$. We used Octopus III (Medtronic, USA) stabilizer and deep pericardial stich. The anastomoses were performed after local stabilization and artery longitudinal incision was followed by intraluminal shunt application. After coronary artery incision, shunts were applied into the lumen of the artery according to their sizes. The shunts were adequate to allow blood flow but to limit bleeding. All anastomoses were performed with running 7-0 monofilament suture.

Patients were provided with written informed consent for surgery but the ethics committee for neither surgical technique nor for shunts application was not required as this type of surgery is common surgical practice. This study is retrospective evaluation of data obtained during standard clinical practice related to operative hospitalizations and outpatient clinics.

The study was conducted in accordance with the Declaration of Helsinki (as revised in 2013). The study was approved by institutional ethics committee of Poznan University of Medical Sciences in Poland with No. 55/20 and informed consent was taken from all the patients.

\section{Patient and public partnership}

The patients were first involved in the research by verifying their survival and participation was voluntary by informing the subject of the study. Survival was additionally assessed by national electronic verification data available for our country.

\section{Statistical analysis}

Continuous variables were reported as mean \pm SD . Categorical variables were reported as frequencies and percentages. Shunts diameters in analyzed groups did not follow the normal distribution, and the differences were evaluated by the Mann-Whitney $\mathrm{U}$ test. The frequencies were compared by test for proportions. Relationship between analyzed parameters was assessed by Spearman's rank correlation coefficient. The Kaplan-Meier estimate was used in order to assess the survival proportions of analyzed subgroups. The significance of survival curves was checked by log-rank test. The Cox's proportional hazards model was performed to analyze potential risk predictors for late overall mortality. The analysis was performed both as univariate and multivariate, which adjust the estimated coefficients to the coexistence of other predictors. The multivariate analysis was performed with stepwise, backward selection procedure. The obtained results were presented as hazard ratios (HRs) and its $95 \%$ confidence intervals (CIs). All tests were considered significant at $\mathrm{P}<0.05$. The analysis was performed by StataCorp. 2019. Stata Statistical Software: Release 16. College Station, TX: StataCorp LLC. All patients included into the study fulfilled the criteria of obtained data. 
Table 1 Demographic and clinical data

\begin{tabular}{|c|c|c|c|}
\hline Parameters & Men subgroup $(n=2,772)$ & Women subgroup $(n=578)$ & $P$ value \\
\hline $\mathrm{BSA}, \mathrm{m}^{2}$, mean $\pm \mathrm{SD}$ & $1.9 \pm 0.2$ & $1.7 \pm 0.3$ & $<0.0001$ \\
\hline Weight, kg & $84 \pm 13$ & $72 \pm 12$ & $<0.0001$ \\
\hline Height, $\mathrm{cm}$ & $171 \pm 7$ & $158 \pm 6$ & $<0.0001$ \\
\hline \multicolumn{4}{|c|}{ Concomitant diseases, n [\%] } \\
\hline Hypertension & 856 [39] & $243[42]$ & 0.1842 \\
\hline Hipercholesterolemia & $1,426[65]$ & $387[67]$ & 0.3664 \\
\hline Diabetes mellitus & $592[27]$ & 166 [29] & 0.3371 \\
\hline
\end{tabular}

$\mathrm{SD}$, standard deviation; BSA, body surface area; kg, kilograms; cm, centimeters; BMI, body mass index.

\section{Results}

There were 2,772 consecutive patients enrolled into the study [2,194 male (79\%) and 578 females (21\%)]. There were no intraoperative deaths in presented group and 30 days mortality rate was $0.5 \%$ (14 patients, 10 men and 4 women). The surgery time was $2.5 \pm 0.8$ hours for men and $2.2 \pm 0.5$ hours for women, respectively $(\mathrm{P}=0.0001)$. After mammary artery and parts of saphenous vein harvesting, the anastomoses were performed. The values of shunts for left anterior descending artery (LAD) were $1.81 \pm 0.3 \mathrm{~mm}$, for circumflex artery $(\mathrm{Cx}) 1.78 \pm 0.3$ and $1.77 \pm 0.3 \mathrm{~mm}$ for right coronary artery (RCA). The anastomoses were performed with single continuous monofilament 7-0 suture.

The number of anastomosed grafts were $2.3 \pm 0.1$ in men and $2.1 \pm 0.2$ in women $(\mathrm{P}<0.0001)$. We used 2,193 left mammary artery grafts, 72 right mammary grafts, 71 left radial arteries and 2,824 venous grafts in the male subgroup. Contrary, 578 left mammary artery grafts, 12 right mammary grafts, 6 left radial arteries and 638 venous grafts were used in the female subgroup. Detailed data are presented in Table 1.

The mean diameters of intraluminal shunts applied during surgery into LAD, Cx and RCA were compared in both subgroups and occurred statistically significant. The diameters of shunt used were: $1.81 \pm 0.28$ vs. $1.7 \pm$ $0.26 \mathrm{~mm}(\mathrm{P}<0.0001)$ during $\mathrm{LAD}$ anastomosis, $1.78 \pm 0.27$ vs. $1.71 \pm 0.29 \mathrm{~mm}(\mathrm{P}<0.0001)$ during $\mathrm{Cx}$ anastomosis and $1.77 \pm 0.28$ vs. $1.72 \pm 0.31 \mathrm{~mm}(\mathrm{P}>0.05)$ during RCA anastomosis, in men and women subgroups, respectively. Detailed information presented in Table 2.

We analyzed the relationship between the mean shunts diameters applied into all three arteries with the BSA. The Spearman's rank correlation between BSA area and mean shunts applied during anastomosis of LAD $(r=0.18$; $\mathrm{P}<0.0001), \mathrm{Cx}(\mathrm{r}=0.11 ; \mathrm{P}<0.0001)$ and $\mathrm{RCA}(\mathrm{r}=0.12$, $\mathrm{P}<0.0001$ ) shows a positive, low correlation. The KaplanMeier analysis shows a significant difference in survival proportions between males and females $(\mathrm{P}<0.0001)$. The 5 -year survival rate was $86 \%$ vs. $94 \%$ and follow-up survival rate was $73 \%$ vs. $94 \%$ for males and females respectively, Figure 1.

We used Cox's proportional hazards model to determine if gender, BSA, coronary arteries diameters and number of applied grafts, were the risk predictors of all-cause mortality. The analysis was performed for whole group of patients and separately for females and male subgroups. The univariate model applied to all patients shows that male sex $[\mathrm{HR}=4.27$; 95\% CI: (2.88-6.30)] is significant risk factor for all-cause mortality. On the contrary, the completeness of revascularization (presented by number of applied grafts) reduces the risk of all-cause mortality [HR $=0.84 ; 95 \%$ CI: (0.74-0.93)]. The same predictors remain statistically significant in multivariate model, Table 3. The sub analysis for males shows similar results. The elevated BSA as well as completeness of revascularization reduces the risk of allcause mortality in males, Table 3. 
Table 2 Surgical data-types of grafts anastomosed during OPCAB procedure

\begin{tabular}{|c|c|c|c|}
\hline Parameters & Men subgroup $(n=2,194)$ & Women subgroup $(n=578)$ & $P$ value \\
\hline \multicolumn{4}{|c|}{ Grafts used/diameter of anastomosis } \\
\hline LIMA, n [\%] & $2,193[99.9]$ & 578 [100] & 0.4469 \\
\hline Mean diameter, mm & $2 \pm 0.9$ & $1.7 \pm 0.6$ & $<0.0001$ \\
\hline Mean diameter, mm & $2 \pm 0.8$ & $1,6 \pm 0.2$ & $<0.0001$ \\
\hline LRA, n [\%] & 71 [3.2] & $6[1]$ & 0.004 \\
\hline Mean diameter, mm & $1.8 \pm 0.3$ & $1.6 \pm 0.7$ & $<0.0001$ \\
\hline SVBG 1, n [\%] & $1,826[83]$ & $437[76]$ & 0.0001 \\
\hline Mean diameter, mm & $1.9 \pm 0.9$ & $1.7 \pm 0.3$ & $<0.0001$ \\
\hline SVBG 3, n [\%] & $51[2.3]$ & $17[3]$ & 0.3324 \\
\hline Mean diameter, $\mathrm{mm}$ & $1.8 \pm 0.4$ & $1.5 \pm 0.2$ & $<0.0001$ \\
\hline
\end{tabular}

OPCAB, off-pump coronary artery bypass; LIMA, left internal mammary artery; mm, millimeters; RIMA, right internal mammary artery; LRA, left radial artery; SVBG, saphenous vein bypass graft.

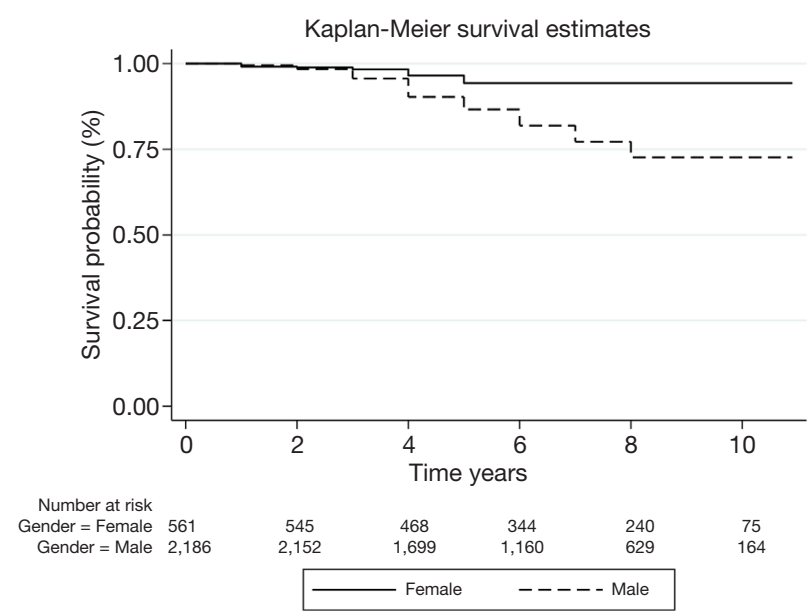

Figure 1 Kaplan-Meier survival differences between genders.

\section{Discussion}

During 130 months of follow up, the male sex, BSA, and completeness of revascularization (presented by mean number of grafts applied) were significant factors for late mortality. Best to our knowledge, this is the first large study of coronary artery diameters based on direct intraluminal shunting application during OPCAB. The previous reports focusing on coronary arteries diameters were based on non-direct calculations of arteries sizes. In our study, coronary arteries diameters were evaluated by shunts which diameters were adjusted to allow blood flow through them without bleeding. This method may have some limitations. Potentially, it may not always reflect the precise intraluminal size of the target coronary artery as blood leakage between the native coronary artery and intraluminal shunt may reflect the actual size of the coronary artery to some extent, but also may be related to degree of coronary artery stenosis or presence of occlusive lesions. However, the method is widely accepted in cardiac surgery and small disproportions seem to be irrelevant.

According to the results of our study, females have smaller coronary artery dimensions evaluated by surgical shunts diameters during performing the anastomosis. The smaller BSA, which is characteristic for women, is also the significant risk factor for smaller diameters of coronary arteries. Despite lower diameters of coronary arteries, the Cox's proportional hazards model finds male sex as significant risk factor for all-cause late mortality following OPCAB grafting. Furthermore, in males, paradoxical, the overweight or obesity reduces the risk of late mortality.

Previous reports involved non-invasive estimation of 
Table 3 The results of Cox proportional-hazards model (univariate and multivariate) for analyzed predictor parameters

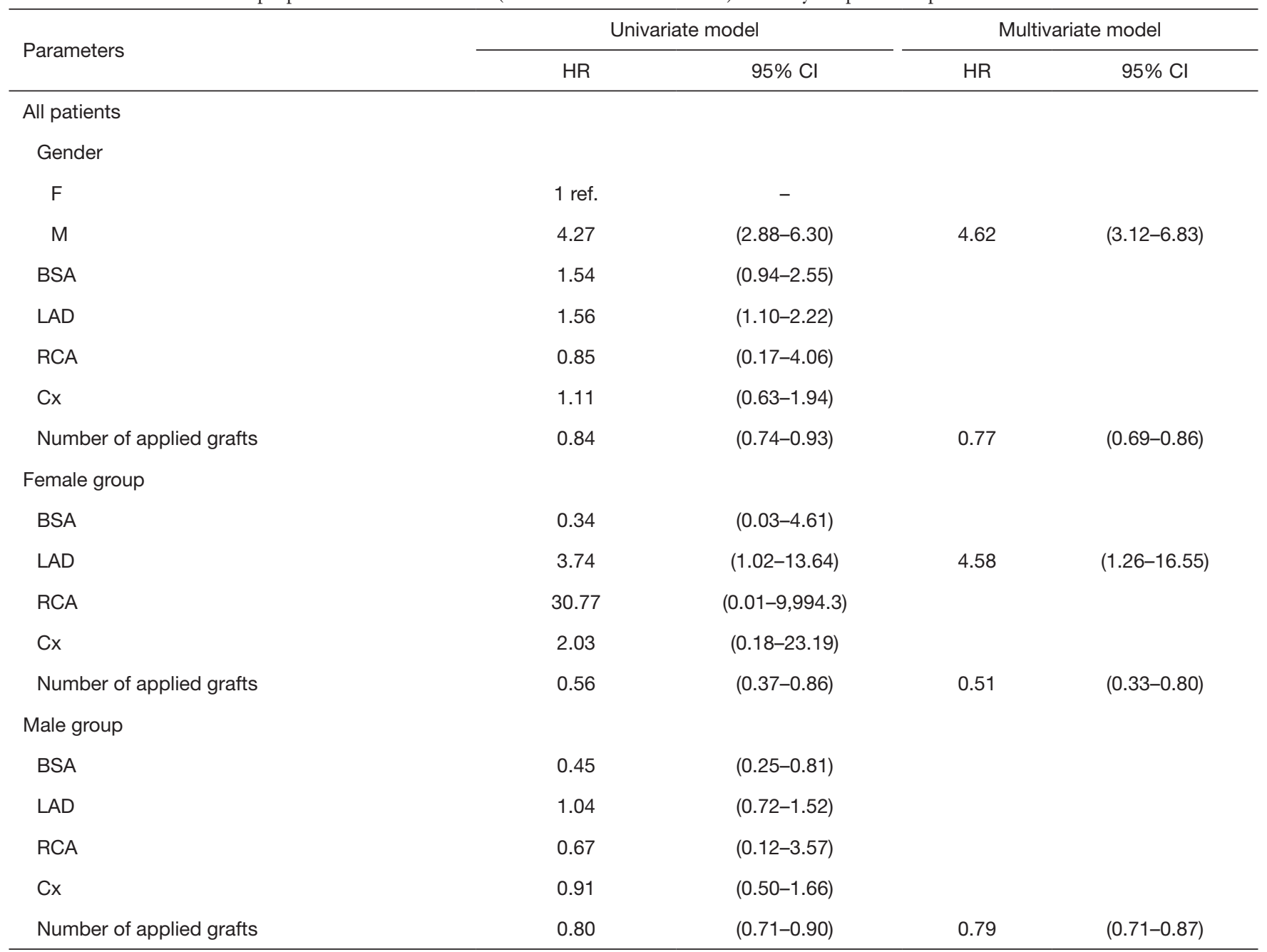

$\mathrm{HR}$, hazard ratio; $\mathrm{Cl}$, confidence interval; F, female; M, male; BSA, body surface area; LAD, left descending artery; RCA, right coronary artery; Cx, circumflex artery.

coronary artery diameters based on computed tomography scans or intravascular ultrasounds results $(8,9)$. The former publications were based on computer calculations, the latter are related to proximal segment measurements $(10,11)$. Our study proves also that BSA is the significant indicator of coronary artery lumen differences. Our suggestion of intraoperative analysis is helpful in practical daily use, does not require additional, detrimental and exams. Lower diameter of coronary arteries in women may explain the observation that mortality rate is higher in ischemic heart disease in women than in men (12). In contrary, all-cause late mortality, according to our results, is lower in women group and confirm the benefit of surgical revascularization. The lower late overall survival in female sex was postulated after percutaneous interventions, though main reasons are non-cardiac (13).

Female gender is an independent risk factor for increased mortality after surgical revascularization. Worse outcome of invasive treatment in CAD in women was proved in several studies (7-16) and therefore female gender was included in predictive preoperative scores, including EuroScore calculator and STS score. Perioperative mortality in our study described by EuroScore II were insignificant between both groups with mean values of $1.16 \pm 0.2$ and $1.21 \pm 0.3$ $(\mathrm{P}=0.0327)$. Results presented in our study confirm the male sex as significant factor for lower all-cause late mortality.

Increased morbidity in females associated with surgical revascularization is attributed to several factors, including 
their smaller coronary artery diameters (6). The late worse results of surgical and percutaneous revascularization in women despite medical advances remain a challenging problem that may be related to differences in coronary arteries diameters. The higher rate of bleeding events, thromboembolic events, procedural complications and lower graft patency were reported (9). The differences in long term results depending on types of grafts utility (arterial $v s$. venous) have a significant impact on clinical outcomes in women (17). Moreover, women benefit more from the $\mathrm{OPCAB}$ technique than from on-pump technique in terms of mid-term mortality, while this difference is not visible in men (18). The difference may result from the bleeding risk, re-exploration needs and red blood transfusions (12).

\section{Study limitation}

It is a single-center study with retrospective analysis based on intraoperative and all-cause mortality data. During surgery none of the patients suffered from active form of neoplasm, but neither previous nor postsurgical history of any oncological disease was taken into consideration estimating all-cause long-term mortality. The study did not refer to the results of surgical technique and did not compare them as the follow up data were not presented. The aim of the study was to compare the overall survival and diameters of the tool used during surgery. The diameters of coronary arteries were assessed on accuracy of the shunt sizes applied during surgery. The diameter of the shunt was adjusted by surgeon to achieve bloodless field.

\section{Conclusions}

Female sex is associated with better late survival following surgical revascularization despite smaller diameters of coronary arteries in direct measurement with the use of intraluminal shunt application.

\section{Acknowledgments}

Funding: None.

\section{Footnote}

Reporting Checklist: The authors have completed the STROBE reporting checklist. Available at http://dx.doi. org/10.21037/jtd-20-3356
Data Sharing Statement: Available at http://dx.doi. org/10.21037/jtd-20-3356

Conflicts of Interest: All authors have completed the ICMJE uniform disclosure form (available at http://dx.doi. org/10.21037/jtd-20-3356). The authors have no conflicts of interest to declare.

Ethical Statement: The authors are accountable for all aspects of the work in ensuring that questions related to the accuracy or integrity of any part of the work are appropriately investigated and resolved. The study was conducted in accordance with the Declaration of Helsinki (as revised in 2013). The study was approved by institutional ethics committee of Poznan University of Medical Sciences in Poland with No. 55/20 and informed consent was taken from all the patients.

Open Access Statement: This is an Open Access article distributed in accordance with the Creative Commons Attribution-NonCommercial-NoDerivs 4.0 International License (CC BY-NC-ND 4.0), which permits the noncommercial replication and distribution of the article with the strict proviso that no changes or edits are made and the original work is properly cited (including links to both the formal publication through the relevant DOI and the license). See: https://creativecommons.org/licenses/by-nc-nd/4.0/.

\section{References}

1. Laslett LJ, Alagona P Jr, Clark BA 3rd, et al. The worldwide environment of cardiovascular disease: prevalence, diagnosis, therapy, and policy issues: a report from the American College of Cardiology. J Am Coll Cardiol 2012;60:S1-49.

2. Tian J, Wang X, Tian J, et al. Gender differences in plaque characteristics of nonculprit lesions in patients with coronary artery disease. BMC Cardiovasc Disord 2019;19:45.

3. Khamis RY, Ammari T, Mikhail GW. Gender differences in coronary heart disease. Heart 2016;102:1142-9.

4. Dickerson JA, Nagaraja HN, Raman SV. Gender-related differences in coronary artery dimensions: a volumetric analysis. Clin Cardiol 2010;33:E44-9.

5. Kłosiewicz-Wasek B, Ceremuzyński L, Poloński L, et al. Association between carotid artery atherosclerosis and coronary artery disease in young females. Reference to sex 
hormone profile. Kardiol Pol 2008;66:127-32; discussion 133-4.

6. Kunadian V, Qiu W, Lagerqvist B, et al. Gender differences in outcomes and predictors of all-cause mortality after percutaneous coronary intervention (data from United Kingdom and Sweden). Am J Cardiol 2017;119:210-6.

7. Maas AH, Appelman YE. Gender differences in coronary heart disease. Neth Heart J 2010;18:598-602.

8. Yiu KH, de Graaf FR, Schuijf JD, et al. Age- and genderspecific differences in the prognostic value of CT coronary angiography. Heart 2012;98:232-7.

9. Hiteshi AK, Li D, Gao Y, et al. Gender differences in coronary artery diameter are not related to body habitus or left ventricular mass. Clin Cardiol 2014;37:605-9.

10. Bowman AW, Kantor B, Gerber TC. Coronary computed tomographic angiography: current role in the diagnosis and management of coronary artery disease. Pol Arch Med Wewn 2009;119:381-90. Erratum in: Pol Arch Med Wewn 2009;119:518.

11. Gasior Z, Pysz P, Dabek J. A contemporary role of coronary artery calcium scoring in the assessment of the risk for coronary artery disease. Pol Arch Med Wewn 2007;117:31-4.

12. Ter Woorst JF, van Straten AHM, Houterman S, et al. Sex difference in coronary artery bypass grafting: preoperative profile and early outcome. J Cardiothorac Vasc Anesth

Cite this article as: Urbanowicz T, Michalak M, Olasińska-Wiśniewska A, Haneya A, Straburzyńska-Migaj E, Bociański $M$, Jemielity $M$. Gender differences in coronary artery diameters and survival results after off-pump coronary artery bypass (OPCAB) procedures. J Thorac Dis 2021;13(5):28672873. doi: $10.21037 /$ jtd-20-3356
2019;33:2679-84.

13. Raphael CE, Singh M, Bell M, et al. Sex differences in long-term cause-specific mortality after percutaneous coronary intervention: temporal trends and mechanisms. Circ Cardiovasc Interv 2018;11:e006062.

14. Heer T, Hochadel M, Schmidt K, et al. Sex differences in percutaneous coronary intervention-insights from the coronary angiography and PCI registry of the German Society of Cardiology. J Am Heart Assoc 2017;6:e004972. Erratum in: J Am Heart Assoc 2017;6:e002331.

15. Puskas JD, Edwards FH, Pappas PA, et al. Off-pump techniques benefit men and women and narrow the disparity in mortality after coronary bypass grafting. Ann Thorac Surg 2007;84:1447-54; discussion 1454-6.

16. Gurram A, Krishna N, Vasudevan A, et al. Female gender is not a risk factor for early mortality after coronary artery bypass grafting. Ann Card Anaesth 2019;22:187-93.

17. Rieß FC, Behrendt CA, Amin W, et al. Complete arterial revascularization using bilateral internal mammary artery in T-graft technique for multivessel coronary artery disease in on- or off-pump approach: does gender lose its historical impact on clinical outcome? Eur J Cardiothorac Surg 2017;52:917-23.

18. Ter Woorst JF, Hoff AHT, Haanschoten MC, et al. Do women benefit more than men from off-pump coronary artery bypass grafting? Neth Heart J 2019;27:629-35. 